\title{
Under the Surface of Images: Low-tech images produced by handheld devices for performance practice
}

\author{
Eunice G. Duarte \\ Atelier Concorde, Portugal \\ http://www.semaforo.cc \\ Eunice.semaforo@gmail.com
}

\begin{abstract}
'Under the surface of images' is a phrase used by Michel Foucault in the book Discipline and Punish when referring to the means in which Surveillance is implicated in the discipline, regulation, and normalisation of the body. Here in this paper is used to understand what can be unveil by low-tech images from two different situations: the first concerns Jazmine Headley's case that had happen in the United States in 2018. The second is related with my practice as an artist and the use of handheld devices in my live performance This is a Low-Tech Movie. In the paper I propose to discuss the use of technology devices as tools for visibility and emotional memory imprint - as described by the neuroscientist Boris Cyrulnik - and how this knowledge can be used in performance practice. The paper is be divided into two main sections, one related to technology and ways of perception, with articles from Jonathan Crary, Camille Barker, and Boris Cyrulnik and, one to the discussion of the concept of 'low-tech image' or 'poor image' produced by handheld devices and developed in my own performance practice.
\end{abstract}

Live performance. Handheld devices. Low-tech image. Spectacle. Neuro-aesthetics. Semiotics of image.

\section{INTRODUCTION}

'Under the surface of images' is a phrase used by Michel Foucault in the book Discipline and Punish when referring to the means in which Surveillance is implicated in the discipline, regulation, and normalisation of the body: "Under the surface of images, one invests bodies in depth" (Crary 1989). Although Foucault's theories pertinency in the discussions of issues concerning images produced by technology and its impact over the individual, I'll leave Foucault for now to focus on an article by art historian Jonathan Crary, 'Spectacle, Attention, Counter-Memory' (1989).

In the article, Crary questions if the origin of Spectacle as developed by Guy Debord in The Society of The Spectacle is linked with the bourgeoisie political revolution in the Nineteenth Century where "for the first time, is that observable proof became necessary to demonstrate that happiness had in fact been obtained" (Crary 1989).

The nineteenth century accounts major changes in social representation, in commodity production and in the strings of power relations where "the spectacle then would coincide with the moment when sign-value takes precedence over use-value" (Crary 1989), or the moment that vision gains privilege over functions. This new visibility is a consequence of the shifts in the place of the observer, Crary claims. The spectacle is thus driven by a visual apparatus that goes beyond the construction of an invisible matrix of control, it also gets expanded to the body and modes of perception.

In this paper, it is my intention to understand how the Spectacle, as a visual apparatus, affects body perception, memory, and emotion. More even, I'm interested in how this research can be used in performance art practice.

The article is divided into two main sections: in the first section I discuss ways of perception produced by a visual apparatus, with articles by Jonathan Crary, Boris Cyrulnik and Camille Baker and, in the second section, I present the concept of 'low-tech image' produced by daily handheld devices, developed in my performance art practice. 


\section{TO APPEAR}

I remember feeling outraged and then having a heavy feeling that there was nothing I could do. The video appeared in my Facebook news feed posted by the New York Times. The framing and the quality of the video drowned me for a few seconds into the uncertainty of what I was seeing but it was the combination of visual misperception with the reading of the caption of the video that glued me to the screen:

A video posted to Facebook showed police officers forcefully removing Jazmine Headley's 1-year-old son from her arms at a Brooklyn food stamp office. The episode ignited outrage online against the New York Police Department and the charges against Ms. Headley were later dropped (NYT 2018)

I then saw the action clearly (Figure 1).

The story is daunting. After waiting for several hours to be attended by a social welfare officer, Jazmine Headley, a single mother living in Brooklyn, and her 1-year-old son were seated on the floor of the welfare office. The security was not keen on the action and ordered her to stand. She refused. The security called the police that ended up arresting Jazmine Headley and taking her baby from her. The story could have become another case of abuse of power by authorities and of dehumanising bureaucratic systems, if not by the several witnesses that captured the arrest with their mobile phones and posted online on Facebook.

"It's the story of many other people. My story is the only one that made it to the surface" (Headley to the NYT 2018). Because it 'made it to the surface', Jazmine Headley is now the face of the struggle that the more deprived have endured within the American bureaucratic system. She is an example of the social asymmetries in her country. To see the video is to see that people like Jazmine exist. I would also argue that the video shows much more than Jazmine's story. It brings to the surface an absurd situation being taken beyond reason but, at the same time, shows the lack of empathy within a system in which we live in and how alienated workers can be from their own humanity.

It is curious however that this case can also be a gap in the system, i.e., it opens a window to acknowledge the several layers in the system. The exposure of the video gives rise to certain images that were under its surface thus making clear its deepest and ugliest layer where horror is kept hidden.

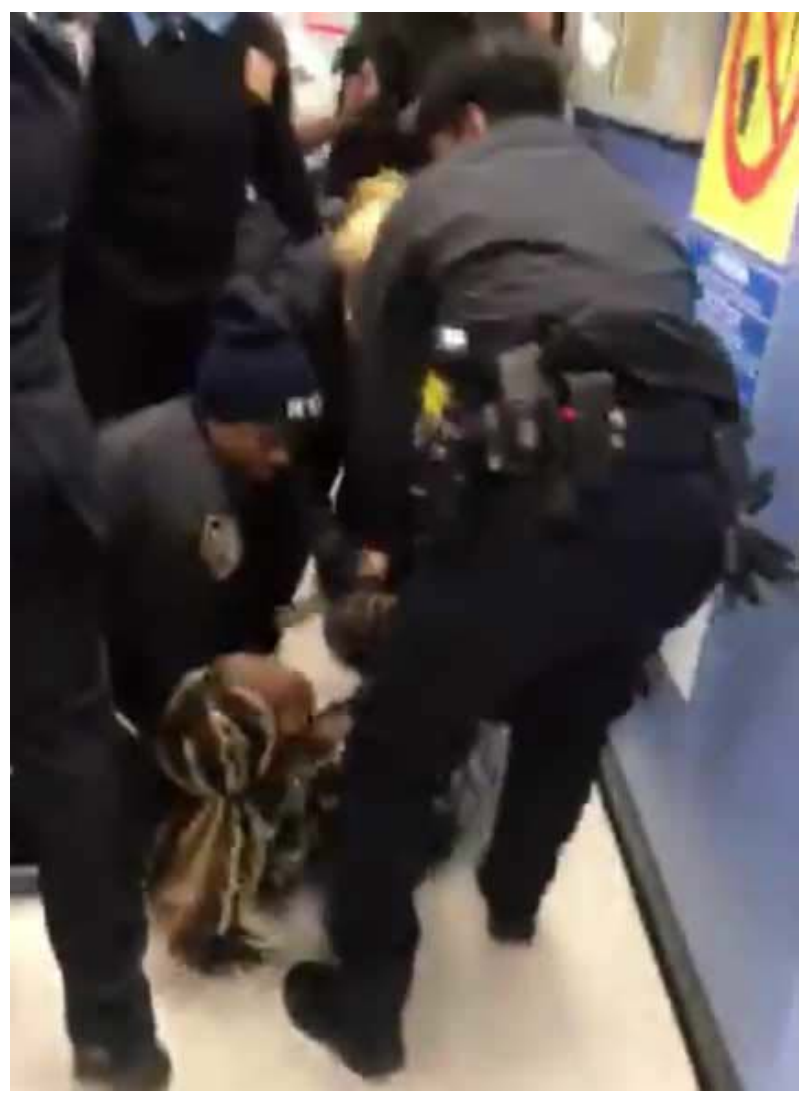

Figure 1: capture from one of videos, recorded by an insite witness using a mobile phone, showing the New York Police forcing Jazmine Headley to let go her baby (that is laid down on her chest). The video is posted at https://heavy.com/news/2018/12/jazmine-headley/)

"For Ms. Headley, the outpouring of sympathy that followed publicity of the arrest has brought her some relief. Her public assistance benefits have been restored" (NYT 2018). This outcome is not just a direct consequence of the action being captured on video but in its streams in social networks: "the Facebook videos have been seen more than 1.3 million times" (NYT 2018). What allured viewers to the video, I advocate, was that the action was presented live, and perceived as a real event.

I saw the video one month after the conflict had happened. I knew its narrative - it was written in the post, alongside with video - and I strongly engaged in it. After seeing it, I could not forget it.

\subsection{Imprinting emotion}

In the article 'Emotion and Trauma' (2013), neuroscientist Boris Cyrulnik describes that a traumatic event impacts memory not for the event itself but because of the psychological effect. It needs to arise in the "neurological circuits that leave a memory potential 'like a scar in brain tissue' (William James) or rather like a path carved out of neuronal undergrowth" (Cyrulnik 2013). To study 
the effects of trauma in the memory, Cyrulnik proposes to differentiate emotion (caused by cerebral stimuli) and feeling (emotion triggered by a mental representation). Emotion works connecting the orbitofrontal cortex to the amygdala and anterior cingulate cortex. The orbitofrontal cortex is responsible for modulating "the affective connotation of events" (Cyrulnik 2013). If the orbitofrontal cortex gets damaged, it won't be able to control the amygdala and by consequence ends up overstimulating the anterior cingulate cortex to the point that "the slightest event triggers uncontrollable emotion" (Cyrulnik 2013) thus making "the motor expression of emotion" uncontrollable as well.

When the overworked amygdala becomes hypertrophic, any feeling that arises from a conflict situation becomes the source of violent stress. It is also the cause for variations of emotion imprinted in the memory:

\begin{abstract}
Amygdala response is what determines whether an item of information is stored in memory. An alert amygdala ensures that some facts will become memory events. A numbed and lesioned amygdala lets nothing through to memory (Cyrulnik 2013).
\end{abstract}

A balanced circuit that travels from the orbitofrontal cortex to amygdala, regulating the anterior cingulate cortex, allows emotion to be imprinted in the brain but with amygdala enlarged [hypertrophic] due to disturbance occurring within the circuit, can provoke memory loss and even indifference. And the more deprived of a sensorial development of emotions and sensations the more the circuit fails to establish connections between the frontal cortex and the anterior cortex.

The sensorial development is traced by Boris Cyrulnik since birth with new-borns learning to read parents and caretakers emotions by body contact. At the core of his research is the Attachment Figure, an 'external base' of security to babies when relating to the world.

\begin{abstract}
A sensory figure featuring at a sensitive moment in a child's development becomes a key object that the child perceives over and above any other. From that point onwards a circuit is traced in its implicit memory, attaching the child to the familiar figure (...) Without such a figure the child panics (...) and is unable to process information correctly. (Cyrulnik 2013)
\end{abstract}

The Attachment Figure gives shelter when the baby experiences fear or a traumatic event. If such a figure fails to exist, the emotion that would allow the baby to gain confidence (an imprint) fails to be retained in the memory creating uncertainty and new information can be overwhelmed and experienced as traumatic. Memory no longer retains an imprint and the interaction with others can be perceived as uncertain once there's no storage of the emotion in the memory.

The result of amygdala enlarged [hypertrophic] is the inability to enjoy life, be indifferent to pain and to lose the ability to feel empathy. Cyrulnik alerts that even the "minor frustrations that are inevitable in daily life (e.g. a delayed feed or temporary absence of its mother for an infant, physical malaise or a relationship issue) cause minor levels of discomfort or distress that train us in empathy" (Cyrulnik 2013).

Going back to Jazmine Headley I would propose that the videos broadcasted live and disseminated in social media would create an emotional response in me - they unveiled what I did not wanted to see in a space (my Facebook feed) that is tailored to my interests. This emotional response occurs, I argue, because of aspects of video settings such as how it is filmed, who filmed it, how it was broadcasted and more importantly to its effects of being authentic.

\subsection{The spectacle of horror}

"We do not need to experience horror in order to strengthen our memory of horrific images. People only have to show one series of horrific images (...) horror has a fascination that fixes memory" (Cyrulnik 2013). We acknowledge the fascination of horror by the Spectacle hence it lives in our daily routines; we only need to think about televised news to understand what this observation is about. What is interesting though is to acknowledge that horror by being recorded, reproduced and repeated will travel more efficiently to memory thus affecting perception and feelings.

\section{Isn't this the effect promoted by the Spectacle?}

I return to Jonathan Crary's article 'Spectacle, Attention, Counter-Memory' and his questioning if late modernism could be in the origins of the Spectacle - promoted by T.J. Clark in his book The Painting of Modern Life. With references to modernism being the antecedent of the Spectacle, Crary criticises Clark for positioning the spectacle as a "form of domination imposed onto a population or individual from without" and "an equivalent for consumer society" (Crary 1989) with an impact mainly over the social structures of society.

Crary argues that Clark disregards the possibility that Spectacle can have an impact on the reorganisation of the subject (body, attention, and memory) and ultimately on "the construction of an observer who was a precondition for the transformation of everyday life" (Crary 1989). 
When researching Guy Debord's post-writings of The Society of The Spectacle, Crary introduced new data regarding the arising of the Spectacle: he claims that it had started in 1927. There were three events to consider that year; all of them related to the introduction of television for the masses 1) Vladimir Zworykin's invention for television function 2) the incorporation of synchronised sound in cinema (with the movie The Jazz Singer) and, the rise of authoritarian regimes with the development of televised propaganda.

A feature of television is that it always incorporated sound and image and when the sound was, for the first time, synchronised with moving images it provoked an overlapping of stimuli in such a manner that a new kind of attention was demanded from the observer. This problematic of attention is referred by Walter Benjamin, also in 1927, in the Arcades Project. For Benjamin, the main concerns were in perception being driven by the increasing use of technology. It provoked a crisis because "of a sweeping remaking of the observer by a calculated technology of the individual, derived from new knowledge of the body" (Crary 1989).

In fact, Crary presents Benjamin's 'standardised and denatured of perception of the masses' in close relation with Henri Bergson's Matter and Memory. According to Crary, Bergson claims that attention "could become transformed into something productive only when it was linked to the deeper activity of memory" (ibid). However, if there is an impoverishment of the memory (provoked by the overlapping of stimulus) and an inhibition of representation of an object then there's a possibility for 'hierarchies of power formations' to happen, that is, images invading the space of perception and being privileged over perception. It also implicates a debilitation of the sensorial development of emotions that can bring deficiencies in the function of emotional memory, described before by Boris Cyrulnik.

By forcing such formation of 'hierarchies of power' among body and senses, a sound and image apparatus (such as the television) can rapidly become an instrument of social control, used firstly by authoritarian regimes and secondly when "corporate power sought home viewing, for maximization of profit" (Crary 1989).

More, towards the end of the article Crary stresses that "television is a further perfecting of panoptic technology" (Crary 1989), opposing Michel Foucault's thesis about society being one of Surveillance and not of Spectacle: "Surveillance and spectacle are not opposed but collapsed onto one another in a more effective disciplinary apparatus" (Crary 1989).
Its effectiveness will improve over time by adding more sophisticated technology. What can happen is that this apparatus stops from being detected, at a stage where it disappears and becomes invisible.

Television entered the intimacy of homes and, once in every household, it was removed from its condition of a device and gradually was transformed into a companion, even holding a place within families.

Regarding horror, television perpetuated the idea of it, not just by showing it but also by creating an environment that intentionally affected the emotion of the observer (live coverage of an event, for example). Thus, there is no need to see a full image of horror, but having the apparatus in motion, all it takes is a suggestion of horror to subsequently recognise it.

Nevertheless, television presents ways of production that are external to the observer. When handheld devices (I'm referring mainly to laptops and mobile phones) became part of everyday life, it brought a closeness to the body that appealed to the intimacy and reflects how we see the world. Camille Baker in the book New Directions in Mobile Media and Performance (2019) describes that a mobile phone has "became beloved for its innate encouragement of spontaneity, and the speed of thought. It enables (...) mixing of ideas and emotion" (Baker 2019)

How can everyday technology (handheld devices) play a role in imprinting emotion in the memory? Also, how can I incorporate such knowledge in my performance practice?

\section{HANDHELD EMOTION}

Camille Baker states that mobile phones offer their users the possibility to engage deeply with the world. The users are able to register, collect and share a personal vision of the world as they "encounter it - the mobile phone becomes the 'window of the world' (...) returning to observing the world in order to capture it, and then finding details that they might not have otherwise noticed" (Baker 2019).

Mobile phones bring immediacy and sharing to the way we communicate. Therefore, what is seen is captured by the lens of the mobile phone and converted into a moment of sharing with a community. At the same time that it is shaped as a fragmentary system (my mobile phone is adjusted to my own needs and wants), mobile phones are connected to a digital community: there is a constant need to reach the other either by expecting a 'like', a comment on a post or just by 
having an impact on the stats. But is the sharing of information bringing an emotional bond with the other?

Camille Baker refers to the importance of the Attachment Figure in babies to strengthen the emotional connection with the other (discussed here in this article). Following this theory, she agrees that physical contact is important for our health but adds the significant role that online communication plays in human interaction: "Friends have reported to me that they can feel the sensation of transmitting or receiving warmth from each other, through emails, text messages, and Skype calls" (Baker 2019), even though this type of connection is just a fraction of the experience or emotion provoked by physical encounter, it can offer different options to long-distance connection with the people we care about.

Can this fraction of emotion be a stimulus that can travel all the way to the memory?

I would argue, yes but also be aware that it is a fraction - it may get lost in context or narrative.

The fraction of the emotion that is represented by a text message, or a Skype call, can have a strong impact on the memory. I can think of two or three friends that were disturbed by the lack of 'likes' in their comments received on their social media accounts. There is no denying that the demand of communication nowadays is intrinsically dependent on these devices.

However, one can argue that iPhones and smartphones don't give enough space for users to experience loneliness or even that it can close the spectrum of sensorial experience that allows emotional stimulus to travel to the memory. Thus, to function smartphones and iPhones demand connection to a WI-FI network. More even, mobile phones push us into the virtual world and into the Spectacle. Still, I defend that by their portability, the effect of immediacy and low-cost production, they can be a means to transform citizens into vigilantes of democracy, producing material such as Jazmine Headley's videos.

I have implied before in this article that the strong emotion provoked by Jazmine Headley's video was not just because of its content but also for the quality of the video and its fast dissemination on the Internet.

The quality of the image in the video is poor, grainy, and sometimes blurry, with exaggerated zooms. The framing is vertical (thus an indicator of a mobile phone capture), and the camera moves constantly (Figure 1). It is far from being shot perfectly. Its true utility is to provoke feelings. We can refer to it as being a video-witness that puts the action into the now - it screams, "this is happening now!" And more importantly, I believe, it imprints an idea of real, of an experience of a real-life event and therefore they are acknowledged as authentic.

Camille Barker described this sense of a real-life momentum captured by the mobile phone lens:

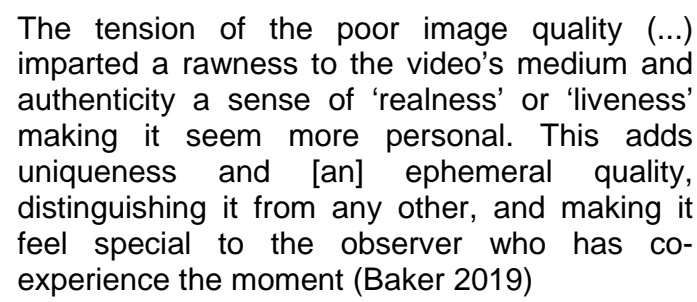
imparted a rawness to the video's medium and authenticity a sense of 'realness' or 'liveness' making it seem more personal. This adds uniqueness and [an] ephemeral quality, distinguishing it from any other, and making it feel special to the observer who has coexperience the moment (Baker 2019)

The videos like the ones of Jazmine Headley being arrested have in themselves a sense of authenticity and of urgency. The observer recognises it as being close to everyday life. As I see it, I do not question its authenticity.

This may happen because there are memories that were shaped by technology. I'm referring to the way we access intimate memories (family memories, for example) through technology - a previous experience of a specific type of image that brings forward the aesthetic of family photos, family videos, and amateur videos. It is with this experience already imprinted in the memory that the representation of the object activates our feelings causing the medium to vanish, to become invisible and the observer to be overwhelmed with an emotion.

The aesthetic of raw image captured by the mobile phone can be transformed into a powerful medium to evoke feelings. Within such aesthetic, a moment that gets captured in a video or in a photo it is not just a token of the moment that is being produced but also a link to the emotional memory of the moment

I have been working with this aesthetic in my own performance practice and I do believe it can bring a valid contribution to performance studies.

\subsection{A low-tech image for performance art}

The transformations that digital media brought to the world are utterly mirrored in art. When I started experimenting with low-tech image in my performance practice, I came across several arguments about the impact that the everyday use of technology was having on the ontology of performance art. Steve Dixon, in the book Digital Performance (2007), describes such a tension between performance and technology. 


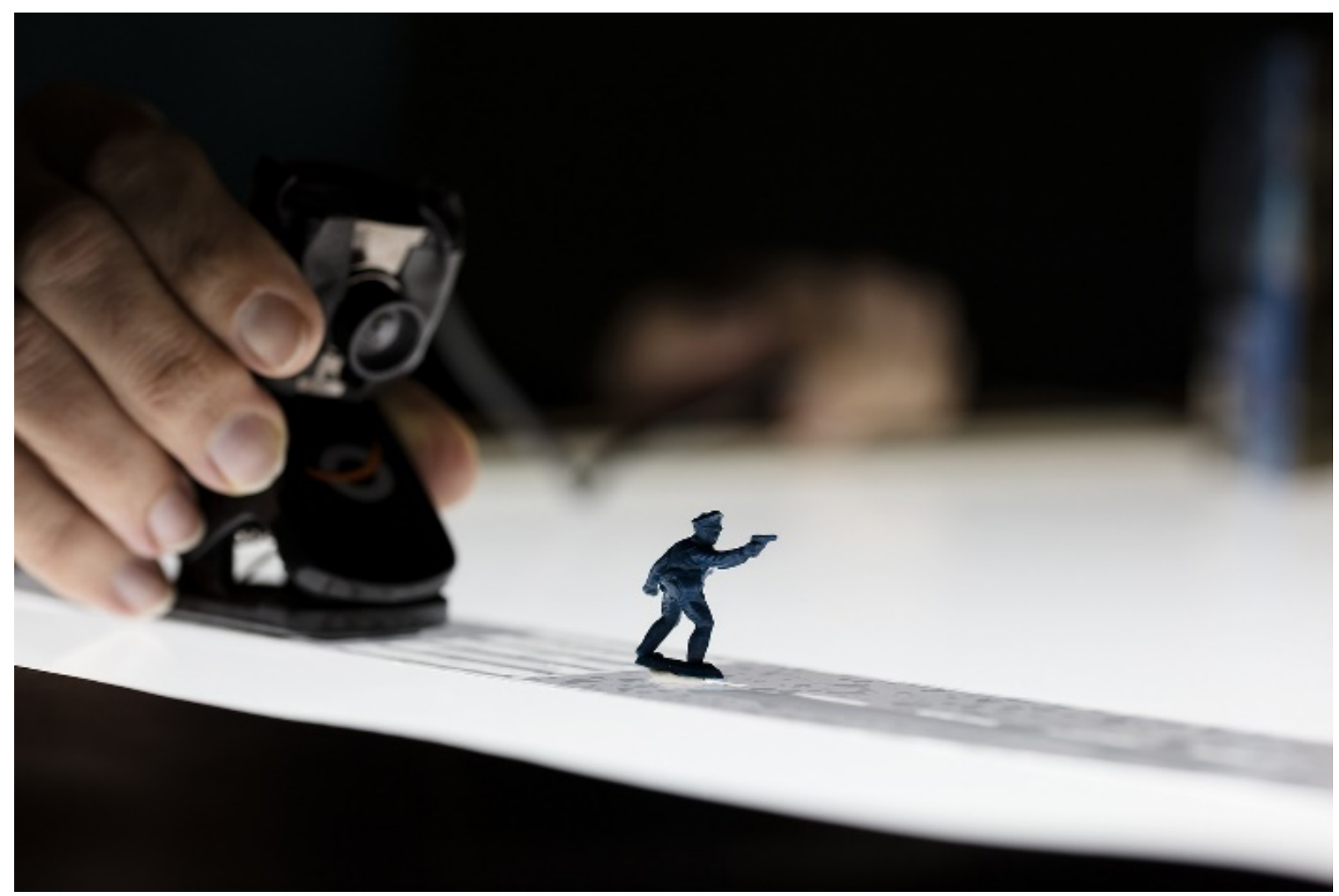

Figure 2: Still from the performance 'This is a Low-Tech Movie' by Eunice Gonçalves Duarte.

Dixon is alert to the negative connotation that was given to the 'virtual' (virtual reality, virtual space and so on) claiming that it has been associated with the notion of 'fake' and 'illusion': "The artificiality or falsehood of digital images has, therefore, limited appeal to many live artists on aesthetic, ideological and political grounds" (Dixon 2007).

The use of digital technologies presents some problems to the ontology of performance and the major criticism of digital performance draws on the issue of 'presence'. Performance is an art of the body, of the physicality of the actor's presence, also in theatrical performance actor and audience are united by a shared physical space.

Dixon points out that such disagreement begins with the concept of performance undertaken by Jerzy Grotowski's poor theatre. With the poor theatre, it is intended to remove everything that is superfluous to the action, narrowing theatre performance to the actor-spectator rapport: "For Grotowski's actors, the via negativa also involved a rigorous stripping away of bodily conditioning and psychological resistances in order to approach pure, animal bodily impulses, and good oldfashioned 'spiritual truth"' (Dixon 2007). To resolve the conflict, Dixon proposes the via positiva where digital performance brings an addition to what already exists.
I would suggest another connection: the concept of poor image promoted by Hito Steyerl in the manifesto 'In Defense of the Poor Image' (2009). Steyerl describes the poor image to be of bad quality: "It is a ghost of an image, a preview, a thumbnail, an errant idea, an itinerant image distributed for free, squeezed through slow digital connections, compressed, reproduced, ripped, remixed, as well as copied and pasted into other channels of distribution" (ibid.).

Steyerl presents the poor image in a close connection between image and viewer. Poor image is presented as a proletarian element that disturbs the hierarchy of images by being in constant change (every token of the image is itself the original image). It can only exist within digital media. In short, it is an image that challenges the Spectacle, creating entropy within the forward flow of the capitalist system (by producing multiples from multiples).

Camille Baker shares a similar opinion in her book but canalizes this urgency to finding new experiences for the mapping of performance artists working with mobile media. Baker states that mobile phones are being used by artists "as a nonverbal visual communication tool (...) to express 'emotion' in the form of media files that represent an interpersonal felt connection over distance" (Baker 2019, p.17). 


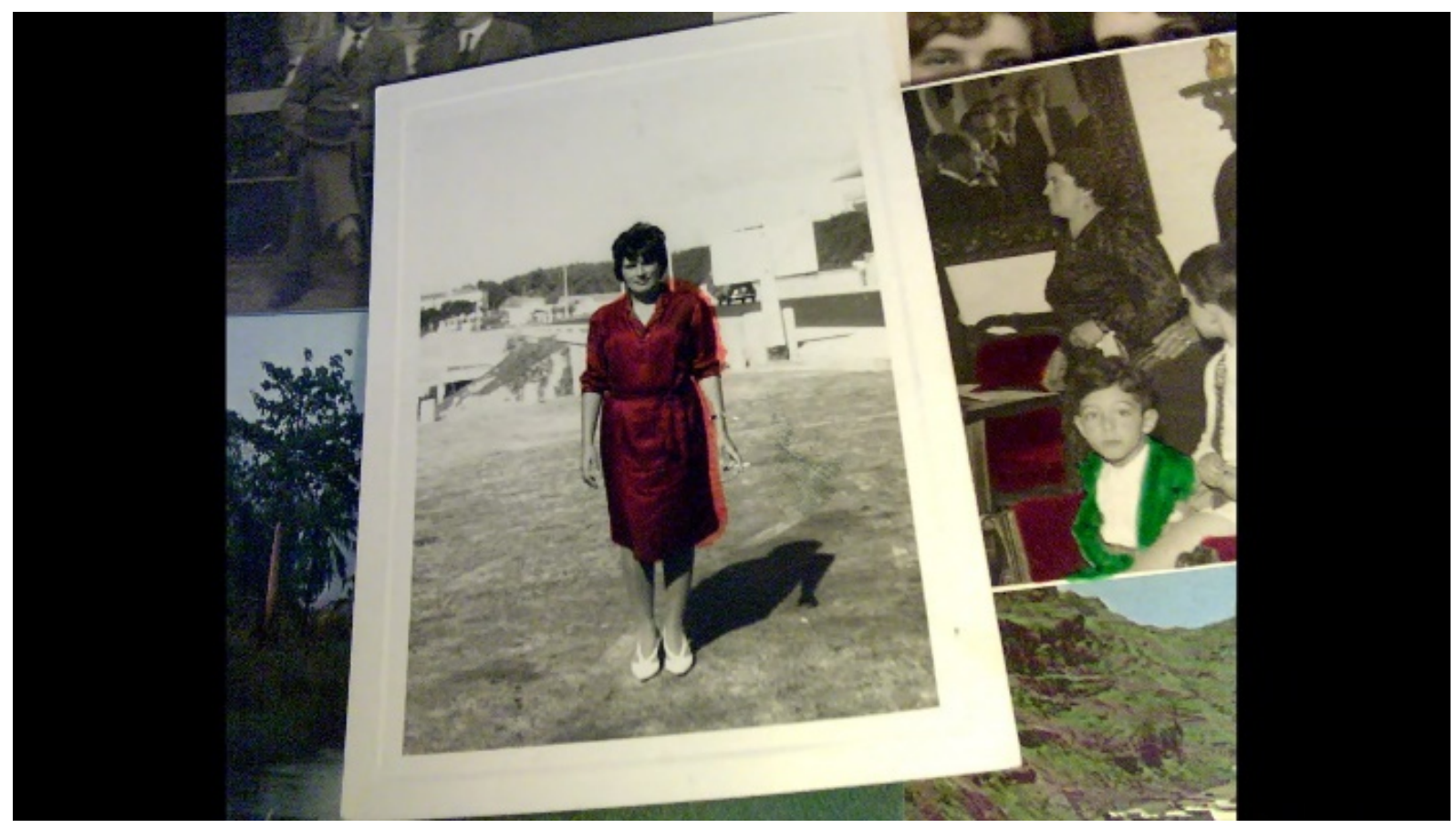

Figure 3: Still from performance 'This is a Low-Tech Movie' by Eunice Gonçalves Duarte.

\subsection{This is a Low-Tech Movie}

Since 2010, I have been working in the concept of producing low-quality images. The low-tech image is a poor image that is produced in a real-time (or simulates real-time). The image is captured by webcams and mobile phones, exploring the relationship with the physical space, the body and with objects. It plays with the limitations of the medium and of the light available on the set. It is not recorded previously to the performance, and only exists for performance purposes. It is ephemeral. Once the performance ends the video disappears.

Each image has a familiarity to it, in a way it brings comfort to the audience because they recognise the images from their own experience, causing the sensation of having seen it somewhere before. It is the image of home videos that quickly capture the moments of everyday life. This type of image does not intend to compete with Cinema, nor television, but attempts to compose an image of affections and memories.

My most recent performance piece This is a LowTech Movie - a performance-installation that attempts to film a movie in real-time - tells the story of three women that for social and political reasons left Portugal to find refuge in other European countries (Figure 2).

This performance incorporates the concept of lowtech image. To create the performance piece, I collected several stories of women that in turmoil situations decided to leave Portugal to find refuge in another European country. From my story collection I have created three new stories and connected it to my family stories.

During the live performance I tell the three stories using family photos, old postcards and elements of nature in micro settings that are displayed over tables (Figure 3). The audience is with me and sees the manipulation of light and webcams to capture action in real-time. There is no editing. All is performed live.

Even though the stories departed from a real situation in someone's life, they are fiction. Nevertheless, I was surprised by the response from the audience to it, they refused to accept it as fiction and imprinted authenticity in the images that were produced in performance.

My hypothesis for such reception is that the medium may have taken over the senses and connected the images with the emotional memory. Therefore, the brain may be identifying a visual narrative that can relate to past experiences. "I can only put in memory what you contribute to it - your emotions, your anger, your smiles. In short, our connection. My autobiographical memory only consists of what you've put into it; it is a relational memory" Cyrulnik says in an interview to the International Review of the Red Cross (2009).

The emotional exchange that happens in This is Low-tech Movie is mediated through images, but this is already something that performance practice do. Nonetheless, Jazmine Headlye's videos helped me to understand that by perceiving her videos as 
authentic, as a real person in a real time situation, she become present to me. Therefore, to appear in such manners is to be made present.

In my performance practice, I dwell in the gaps of the non-existing image. I consider my concept of low-tech image inscribed into a militancy of bringing women their legitimate visibility. I produce an image that can compensate for the lack of visual material of women taking part in historical moments.

I believe my practice contributes towards the understanding of the relation between performance - technology - society, strongly bound in an image that is an expression of emotion. With it, I expect to explore the technological aspects of Spectacle and use technology as a way of counter-spectacle i.e. using the same devices that produce 'the visible' and show the invisible fringes of art and of society.

\section{REFERENCES}

Baker, C. (2019) New Directions in Mobile Media and Performance. New York, Routledge.

Bouvier, P. (2019), 'Interview with Boris Cyrulnik' in International Review of the Red Cross, 101, Memory and Trauma. Cambridge University Press, pp.11-36.
Benjamin, W. (1992), 'A Obra de Arte na Era da sua Reprodutibilidade Técnica' in Sobre Arte, Técnica, Linguagem e Política, Lisbon, Relógio d'Água, pp.73-110 [Portuguese translation].

Cyrulnik, B. (2013), 'Emotion and Drama' in Medicographia, N. ${ }^{\circ} 116$ [Vol 35, No. 3], A Servier Publication, pp.265-270.

Crary, J. (1989) 'Spectacle, Attention, CounterMemory' (1989), October, 50 (Autumn, 1989), pp.96-107

Dixon, S. (2007), Digital Performance: A History of New Media in Theatre, Dance, Performance Art and Installation. Cambridge, MIT Press Books

Southall, A. and Stuart, N. (2018), 'The Grabbed Her Baby and Arrested Her. Now Jazmine Headley is Speaking Out', The New York Times, 16 December 2018.

Steyerl, H. (2009) 'In Defence of the Poor Image', E-Flux, 10, November. https://www.eflux.com/journal/10/61362/in-defense-of-the-poorimage/ (retrieved 1 January 2016). 